\title{
Structural Characterization of (Arylimido)vanadium(V) Compounds with 2,6-Difluorophenoxide Ligand
}

\author{
Toshiyuki Moriuchi, Takashi Sakuramoto, Masafumi Nishina, \\ Ryota Kawai, Toshikazu Hirao
}

\begin{tabular}{|c|l|}
\hline \multicolumn{1}{|c|}{ Citation } & Zeitschrift für anorganische und allgemeine Chemie, 643(18): 1173-1177 \\
\hline Issue Date & $2017-10-04$ \\
\hline Type & Journal Article \\
\hline Textversion & Author \\
\hline & $\begin{array}{l}\text { This is the peer reviewed version of the following article: MORIUCHI, T., } \\
\text { SAKURAMOTO, T., NISHINA, M., KAWAI, R., \& HIRAO, T. (2017). Structural } \\
\text { Characterization of (Arylimido)vanadium(V) Compounds with 2,6-Difluorophenoxide } \\
\text { Ligand. Zeitschrift Für Anorganische Und Allgemeine Chemie. 643, 1173-1177., } \\
\text { which has been published in final form at https://doi.org/10.1002/zaac.201700205 }\end{array}$ \\
& $\begin{array}{l}\text { This article may be used for non-commercial purposes in accordance with Wiley } \\
\text { Terms and Conditions for Self-Archiving. }\end{array}$ \\
\hline DOI & \begin{tabular}{l}
$10.1002 /$ zaac.201700205 \\
\hline
\end{tabular}
\end{tabular}

\author{
Self-Archiving by Author(s) \\ Placed on: Osaka City University
}

MORIUCHI, T., SAKURAMOTO, T., NISHINA, M., KAWAI, R., \& HIRAO, T. (2017). Structural Characterization of (Arylimido)vanadium(V) Compounds with 2,6-Difluorophenoxide Ligand. Zeitschrift Für Anorganische Und Allgemeine Chemie. 643, 1173-1177. 


\title{
Structural Characterization of (Arylimido)vanadium(V) Compounds with 2,6-Difluorophenoxide Ligand
}

\author{
Toshiyuki Moriuchi, ${ }^{*[a]}$ Takashi Sakuramoto, ${ }^{[a]}$ Masafumi Nishina, ${ }^{[a]}$ Ryota Kawai, ${ }^{[a]}$ and Toshikazu \\ Hirao*[a]
}

\begin{abstract}
The (arylimido)vanadium(V) compound, [(p$\left.\mathrm{MeOC}_{6} \mathrm{H}_{4} \mathrm{~N}\right) \mathrm{V}\left(\mathrm{O}^{\prime} \mathrm{Pr}\right)_{3}$ ] was demonstrated to undergo ligand exchange reaction with one or two equivalents of 2,6-difluorophenol, affording the (arylimido)vanadium( $(\mathrm{V})$ compounds, $\left[\left(p-\mathrm{MeOC}_{6} \mathrm{H}_{4} \mathrm{~N}\right) \mathrm{V}\left(\mathrm{O}^{\prime} \mathrm{Pr}\right)_{2}(\mathrm{O}-\right.$ $\left.\left.2,6-\mathrm{F}_{2} \mathrm{Ph}\right)\right]$ and $\left[\left(p-\mathrm{MeOC}_{6} \mathrm{H}_{4} \mathrm{~N}\right) \mathrm{V}\left(\mathrm{O}^{\prime} \mathrm{Pr}\right)\left(\mathrm{O}-2,6-\mathrm{F}_{2} \mathrm{Ph}\right)_{2}\right]$. Their X-ray crystallographic analyses elucidated the $\mu$-isopropoxido-bridged dimeric structures, wherein each vanadium atom has a trigonalbipyramidal geometry with the imido and bridging isopropoxide ligands in the apical positions. The isopropoxide ligand was selectively employed as a bridging ligand between two vanadium centers. On the other hand, the reaction of the (arylimido)vanadium(V) compound, $\left[\left(p-\mathrm{MeOC}_{6} \mathrm{H}_{4} \mathrm{~N}\right) \mathrm{VCl}_{3}\right]$ and three equivalents of lithium 2,6difluorophenoxide gave the (arylimido)vanadium( $\mathrm{V})$ compound, [ $p$ $\left.\left.\mathrm{MeOC}_{6} \mathrm{H}_{4} \mathrm{~N}\right) \mathrm{V}\left(\mathrm{O}-2,6-\mathrm{F}_{2} \mathrm{Ph}\right)_{3}\right]$. In the crystal packing, the thus-obtained compound showed a distorted trigonal-bipyramidal geometry at the vanadium atoms with the $\mu$-phenoxido-bridged dimeric structure, wherein the 2,6-difluorophenoxide ligand was found to serve as a bridging ligand
\end{abstract}

\section{Introduction}

The imido ligands are known to play a key role for stabilization of transition metal complexes in high oxidation states $^{[1]}$ through a metal-nitrogen multiple bond, ${ }^{[2]}$ wherein the imido ligand coordinates to metal centers and can serve as an ancillary or supporting ligand. (Imido)vanadium(V) compounds have drawn much attention ${ }^{[3]}$ to design a catalyst for polymerization of olefin, ${ }^{[4]} \mathrm{C}-\mathrm{H}$ bond activation, ${ }^{[5]}$ and other reactions, ${ }^{[6]}$ in which ligands connected to the vanadium metal center have been demonstrated to play an important role in the reactivity. ${ }^{[4 a, h, 6 f]}$ (Imido)vanadium(V) compounds with alkoxide ligands are known to dimerize through $\mu$-alkoxido-bridging in the crystal structures. ${ }^{[3 \mathrm{c},-\mathrm{j}-\mathrm{k}, \mathrm{m}, \mathrm{o}, \mathrm{r}, 4 \mathrm{c}]}$ In the case of the (ptolylimido)vanadium trichloride, the polymeric structure with two chloride bridges was reported. ${ }^{[7]}$ Self-association to the $\mu$ alkoxido-bridged dimeric structures has been demonstrated in the case of the (aryllimido)vanadium dialkoxychloride ${ }^{[3 c]}$ and the (aryllimido)vanadium alkoxydichloride ${ }^{[6]}{ }^{[n}$ indicating that tha dimeric species are more likely to form the alkoxido-bridging

[a] Dr. T. Moriuchi, T. Sakuramoto, Dr. M. Nishina, R. Kawai, Prof. Dr. T. Hirao

Department of Applied Chemistry, Graduate School of Engineering Osaka University

Yamada-oka, Suita, Osaka 565-0871 (Japan)

Fax: (+81) 6-6879-7415

E-mail: moriuchi@chem.eng.osaka-u.ac.jp hirao@chem.eng.osaka-u.ac.jp

Supporting information for this article is available on the WWW under http://dx.doi.org species rather than the chlorido-bridging ones. Fluorinesubstituted phenoxide ligands are likely to enhance the Lewis acidity of coordinated vanadium atoms because fluoro substituents work as an electron-withdrawing group. Moreover, this Lewis acid properties are expected to cause the selfassociation of (imido)vanadium( $\mathrm{V})$ compounds with fluorinesubstituted phenoxide ligands such as pentafluorophenoxide ligand through $\mu$-phenoxido-bridging ${ }^{[49]}$. However, selectivity of the alkoxide bridging ligand in the $\mu$-alkoxido-bridged dimeric (imido)vanadium(V) compounds with two types of alkoxide ligands has not been investigated. To gain insight into the selfassociation properties of the (arylimido)vanadium compounds, we herein report the structural characterization of (arylimido)vanadium(V) compounds with 2,6-difluorophenoxide ligands to clarify the effect of the phenoxide ligands in the selfassociation

\section{Results and Discussion}

The 2,6-difluorophenoxide ligand was introduced through the ligand exchange reaction of the (arylimido)vanadium(V) compound, $\left[\left(p-\mathrm{MeOC}_{6} \mathrm{H}_{4} \mathrm{~N}\right) \mathrm{V}\left(\mathrm{O}^{\prime} \mathrm{Pr}\right)_{3}\right]$ (1) with one or two equivalents of 2,6-difluorophenol in dichloromethane at room temperature, resulting in the formation of the (arylimido)vanadium $(\mathrm{V})$ compounds, $\left[\left(p-\mathrm{MeOC}_{6} \mathrm{H}_{4} \mathrm{~N}\right) \mathrm{V}\left(\mathrm{O}^{\prime} \mathrm{Pr}\right)_{2}(\mathrm{O}-\right.$ $\left.\left.2,6-\mathrm{F}_{2} \mathrm{Ph}\right)\right](\mathbf{2 a})$ or $\left[\left(p-\mathrm{MeOC}_{6} \mathrm{H}_{4} \mathrm{~N}\right) \mathrm{V}\left(\mathrm{O}^{\prime} \mathrm{Pr}\right)\left(\mathrm{O}-2,6-\mathrm{F}_{2} \mathrm{Ph}\right)_{2}\right](\mathbf{3 a})$, as shown in Scheme 1. The (arylimido)vanadium $(\mathrm{V})$ compound with three 2,6-difluorophenoxide ligands, $\left[\left(p-\mathrm{MeOC}_{6} \mathrm{H}_{4} \mathrm{~N}\right) \mathrm{V}(\mathrm{O}-2,6-\right.$ $\left.\left.\mathrm{F}_{2} \mathrm{Ph}\right)_{3}\right] \quad(\mathbf{5 a})$, was synthesized by the reaction of the (arylimido)vanadium(V) compound, [( $\left.\left.p-\mathrm{MeOC}_{6} \mathrm{H}_{4} \mathrm{~N}\right) \mathrm{VCl}_{3}\right](4)$, with three equivalents of lithium 2,6-difluorophenoxide in dichloromethane at room temperature. These (arylimido)vanadium(V) compounds are characterized by ${ }^{1} \mathrm{H}$ NMR, ${ }^{13} \mathrm{C} \mathrm{NMR},{ }^{51} \mathrm{~V} \mathrm{NMR}$, elemental analyses, and crystallographic analyses.

The ligand exchange effect on the electronic environment of the vanadium center was examined by ${ }^{51} \mathrm{~V}$ NMR measurement. The ${ }^{51} \mathrm{~V}$ chemical shift of the (arylimido)vanadium( $\left.\mathrm{V}\right)$ compound 1 with triisopropoxide was reported to be observed at $-602 \mathrm{ppm}$ (measured in $\mathrm{CD}_{2} \mathrm{Cl}_{2}$ solution). ${ }^{[3 \mathrm{~m}]}$ In the ${ }^{51} \mathrm{~V}$ NMR of the (arylimido)vanadium(V) compound with 2,6-difluorophenoxide ligands, the ${ }^{51} \mathrm{~V}$ chemical shift was observed at a lower field as increasing the amount of the introduced 2,6-difluorophenoxide ligands (2a: $-532 \mathrm{ppm}, \mathbf{3 a}:-367 \mathrm{ppm}, \mathbf{5 a}:-241 \mathrm{ppm})$, probably because of the electron-withdrawing properties of the 2,6difluorophenoxide ligand. The ${ }^{51} \mathrm{~V}$ chemical shifts suggest that (arylimido)vanadium( $\mathrm{V}$ ) compounds are likely to be monomeric in the solution state because the chemical shifts of $\mathbf{2 a}, \mathbf{3 a}$, and $\mathbf{5 a}$ are close to those of other monomeric (arylimido)vanadium $(\mathrm{V})$

For internal use, please do not delete. Submitted_Manuscript 


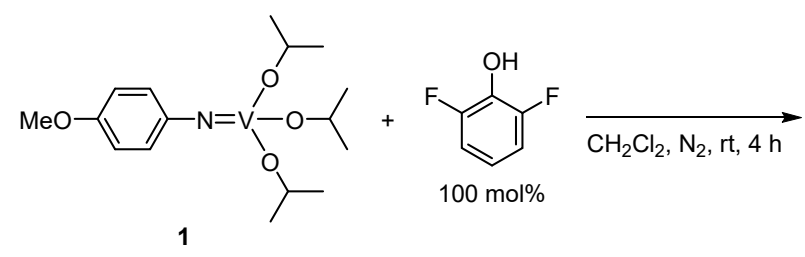<smiles>COc1ccc(N=P(Oc2c(F)cccc2F)(OC(C)C)OC(C)C)cc1</smiles><smiles>COc1ccc(N=P(OC(C)C)(OC(C)C)OC(C)C)cc1</smiles><smiles>Oc1c(F)cccc1F</smiles>

$\overrightarrow{\mathrm{CH}_{2} \mathrm{Cl}_{2}, \mathrm{~N}_{2}, \mathrm{rt}, 4 \mathrm{~h}}$<smiles>COc1ccc(N=P(Oc2c(F)cccc2F)(Oc2c(F)cccc2F)OC(C)C)cc1</smiles>

3a<smiles>COc1ccc(N=[N+](N=C2CC3CCCC2C3)Oc2c(F)cccc2F)cc1</smiles>

5a

Scheme 1. The synthesis of the (arylimido)vanadium(V) compound 2a, 3a, an 5a with 2,6-difluorophenoxide ligand.

compounds. The ${ }^{51} \mathrm{~V}$ chemical shifts of dimerized (arylimido)vanadium( $\mathrm{V})$ compounds are observed in the lower field than the those of $\mathbf{2} \mathbf{a}, \mathbf{3} \mathbf{a}$, and $\mathbf{5} \mathbf{a}^{[3 t]}$. Moreover, the (arylimido)vanadium( $\mathrm{V}$ ) compound $\mathbf{2 a}$ show the only one kind of isopropyl resonance in the ${ }^{1} \mathrm{H}$ NMR as an evidence for maintaining a monomeric structure in the solution state.

$\left[\left(p-\mathrm{MeOC}_{6} \mathrm{H}_{4} \mathrm{~N}\right) \vee\left(\mathrm{O}^{\prime} \mathrm{Pr}\right)_{3}\right](\mathbf{1})^{[3 \mathrm{~m}]}$ has been demonstrated to form the $\mu$-alkoxido-bridged dimeric structure through self-

\begin{tabular}{lll}
\hline \multicolumn{2}{l}{ Table 1. Crystallographic date for $\mathbf{3 a}$ and $\mathbf{5 a}$} & \\
\hline & $\mathbf{3 a}$ & $\mathbf{5 a}$ \\
\hline Empirical formula & $\mathrm{C}_{22} \mathrm{H}_{20} \mathrm{~N}_{1} \mathrm{O}_{4} \mathrm{~F}_{4} \mathrm{~V}$ & $\mathrm{C}_{25} \mathrm{H}_{16} \mathrm{~N}_{1} \mathrm{O}_{4} \mathrm{~F}_{6} \mathrm{~V}$ \\
Formula weight & 489.34 & 559.34 \\
Crystal system & monoclinic & monoclinic \\
Space group & $P 2{ }_{1} / c(\mathrm{No} .14)$ & $P 21 / n($ No. 14$)$ \\
$a(\AA)$ & $10.1447(5)$ & $10.1840(10)$ \\
$b(\AA)$ & $13.0988(6)$ & $14.5348(14)$ \\
$c(\AA)$ & $17.7758(8)$ & $15.9633(15)$ \\
$\beta\left({ }^{\circ}\right)$ & $103.6790(11)$ & $92.818(3)$ \\
$V\left(\AA^{3}\right)$ & $2295.10(18)$ & $2360.1(4)$ \\
$Z$ & 4 & 4 \\
$D$ calcd $\left(\mathrm{g} \mathrm{cm}{ }^{-3}\right)$ & 1.416 & 1.574 \\
$\mu(\mathrm{Mo} \mathrm{K \alpha})\left(\mathrm{cm}^{-1}\right)$ & 4.914 & 5.007 \\
$T\left({ }^{\circ} \mathrm{C}\right)$ & 23 & -150 \\
$\lambda(\mathrm{Mo} \mathrm{K \alpha})(\AA)$ & 0.71075 & 0.71075 \\
$R 1{ }^{[a]}$ & 0.0650 & 0.0681 \\
$w R 2{ }^{[\mathrm{b}]}$ & 0.2324 & 0.1307 \\
\hline
\end{tabular}

[a] $R 1=\Sigma|| F_{0}|-| F_{\mathrm{c}}|| \Sigma\left|F_{\mathrm{o}}\right| \cdot[\mathrm{b}] w R 2=\left[\Sigma w\left(F_{0}^{2}-F_{\mathrm{c}}^{2}\right)^{2} / \Sigma w\left(F_{0}^{2}\right)^{2}\right]^{1 / 2}$. association. To clarify the association properties of (arylimido)vanadium(V) with phenoxide ligands, X-ray crystal structure analyses were performed (Table 1 ). Diffraction-quality single crystal of the compound $\mathbf{2 a}$ with one 2,6-difluorophenoxide ligand was given by diffusion of hexane into toluene solution of $2 \mathbf{a}$. Although the $R 1$ value of $2 \mathbf{a}$ is large probably due to low quality of the crystal, the compound $2 \mathbf{a}$ was found to form a $\mu$ isopropoxido-bridged dimeric structure $\mathbf{2 b}$ in the crystal packing (Figure S1 in the Supporting Information) as observed in the crystal structures of the trialkoxides, ${ }^{[3 j-k, m, o, r]}$ dialkoxides, ${ }^{[3 c]}$ and alkoxide compounds. ${ }^{[6]}$ Herein, each vanadium atom has a trigonal-bipyramidal geometry $(\tau=0.93)^{[8]}$ with the imido ligand and bridging isopropoxide ligand in the apical positions.

Single crystal suitable for single-crystal X-ray structure determination was obtained by the diffusion of hexane into dichloromethane solution of $3 a$. The selected bond lengths and angles were listed in Table 2. From the results of X-ray crystallographic analysis, the compound $3 a$ showed a $\mu$ isopropoxido-bridged dimeric structure $\mathbf{3 b}$ (Figure 1a) with a trigonal-bipyramidal geometry at each vanadium atom $(\tau=0.99)^{[8]}$ similarly to $\mathbf{2 b}$. Herein, the imido ligand and the bridging isopropoxide ligand are in the apical position. Compared with $\mathbf{1}$, the compound 3a showed a little shorter V-N imido bond due to the introduction of the 2,6-difluorophenoxide ligand. The axial V1$01^{*}$ bond is $0.38 \AA$ longer than the equatorial V1-O1 bond in the bridging isopropoxy group. The long axial $\mathrm{V}-\mathrm{O}$ distance trans to the imido ligand suggests the weaker coordination. Moreover, the introduction of two phenoxide ligands was found to induce two

For internal use, please do not delete. Submitted_Manuscript 

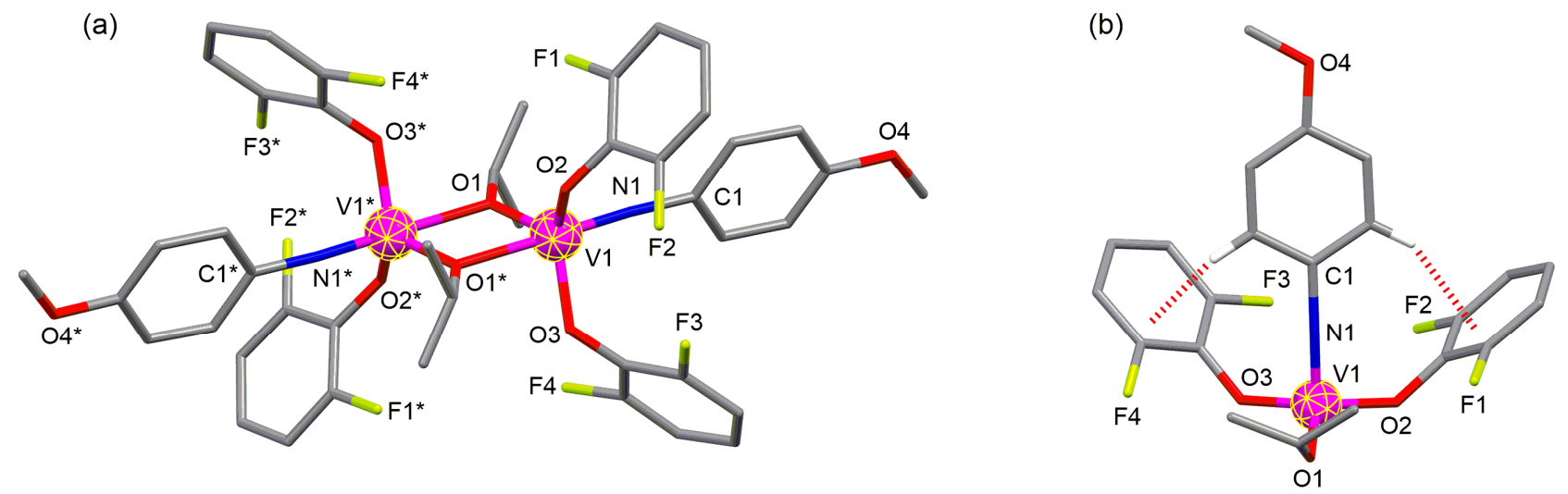

Figure 1. (a) The $\mu$-isopropoxido-bridged dimeric structure of $\mathbf{3 b}$ and (b) $\mathrm{CH}-\pi$ interactions in the crystal structure of $\mathbf{3 a}$ (hydrogen atoms are omitted for clarify).

(a)

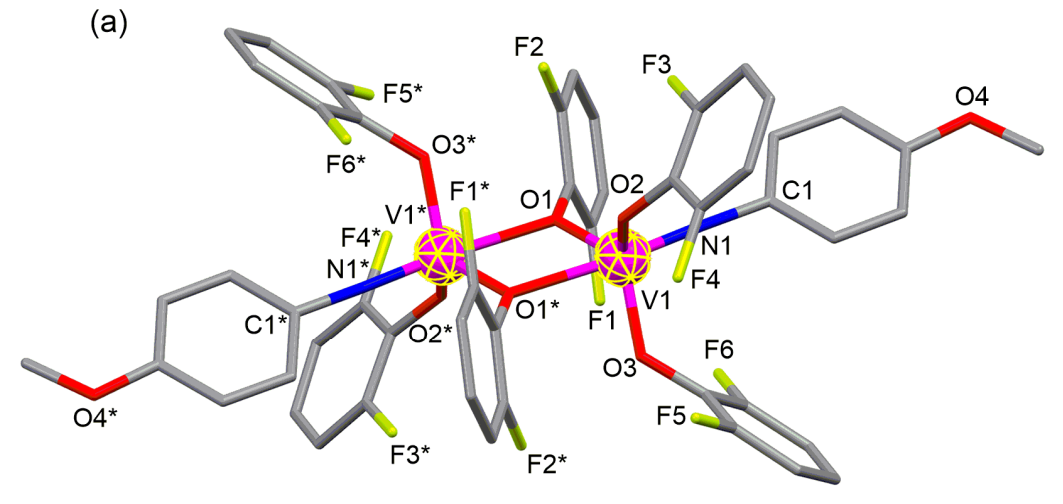

(b)

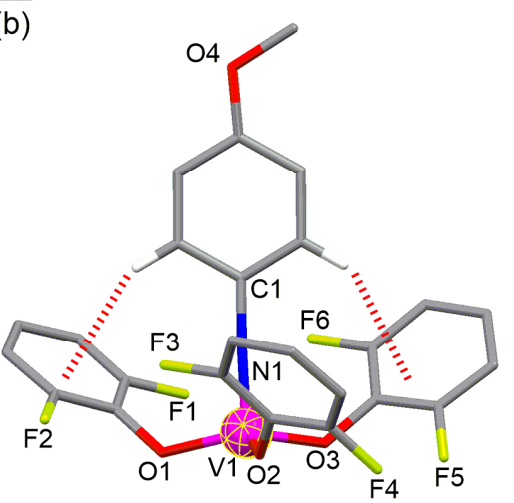

Figure 2. (a) The $\mu$-phenoxido-bridged dimeric structure of $\mathbf{5 b}$ and (b) $\mathrm{CH}-\pi$ interactions in the crystal structure of $\mathbf{5 a}$ (hydrogen atoms are omitted for clarify).

Table 2. Selected bond lengths $(\AA)$ and angles $\left({ }^{\circ}\right)$ for $\mathbf{1}, 3$ a and $\mathbf{5 a}$

\begin{tabular}{|c|c|c|c|}
\hline & $1^{[a]}$ & $3 a$ & $5 a$ \\
\hline \multicolumn{4}{|l|}{ Bond Lengths } \\
\hline V1-N1 & $1.677(2)$ & $1.659(3)$ & $1.656(3)$ \\
\hline V1-O1 & $1.843(2)$ & $1.826(2)$ & $1.884(2)$ \\
\hline V1-O2 & 1.794(2) & $1.831(3)$ & $1.809(3)$ \\
\hline V1-O3 & 1.792(3) & $1.836(3)$ & $1.809(3)$ \\
\hline $\mathrm{V} 1-\mathrm{O} 1^{*[\mathrm{~b}]}$ & $2.245(1)$ & $2.202(2)$ & $2.229(2)$ \\
\hline C1-N1 & $1.368(2)$ & $1.389(4)$ & $1.385(5)$ \\
\hline \multicolumn{4}{|l|}{ Bond Angles } \\
\hline C1-N1-V1 & $177.3(2)$ & $174.7(3)$ & $177.6(3)$ \\
\hline $\mathrm{V} 1-\mathrm{O} 1-\mathrm{V} 1^{*[\mathrm{~b}]}$ & $107.03(7)$ & $105.48(10)$ & $108.24(11)$ \\
\hline N1-V1-O1 & 101.92(9) & $102.96(12)$ & $100.70(13)$ \\
\hline N1-V1-O2 & $101.85(9)$ & $100.24(15)$ & $101.46(13)$ \\
\hline N1-V1-O3 & $101.0(1)$ & $98.27(14)$ & $100.88(13)$ \\
\hline $\mathrm{N} 1-\mathrm{V} 1-\mathrm{O} 1$ * [b] & $174.88(9)$ & $177.26(13)$ & $172.45(13)$ \\
\hline O1-V1-O2 & $116.93(10)$ & $117.93(12)$ & 119.36(11) \\
\hline O1-V1-O3 & $117.45(9)$ & $115.69(13)$ & $119.29(11)$ \\
\hline O1-V1-O1*[b] & $72.97(7)$ & $74.52(9)$ & $71.76(10)$ \\
\hline O2-V1-O3 & $113.78(10)$ & 116.64(12) & $110.65(12)$ \\
\hline $\mathrm{O} 2-\mathrm{V} 1-\mathrm{O} 1 *[\mathrm{~b}]$ & $81.13(6)$ & $82.01(11)$ & $82.99(10)$ \\
\hline O3-V1-O1*[b] & 81.35(8) & $82.03(10)$ & $83.02(10)$ \\
\hline
\end{tabular}

[a] Reference $3 m$. [b] $-x+1 / 2,-y+1 / 2+2,-z+1$. intramolecular $\mathrm{CH}-\pi$ interaction between hydrogen atoms at the ortho position of the methoxyphenyl moiety and phenoxide ligands (Figure 1b). The V1-N1 distance of 1.659(3) $\AA$ and the V1$\mathrm{N} 1-\mathrm{C} 1$ angle of $174.7(3)^{\circ}$ were observed in $3 \mathrm{a}$, suggesting an sphybridized character in the imido nitrogen. The $\mathrm{V} 1-\mathrm{V} 1^{*}$ internuclear distance of $3.21 \AA$ indicates the absence of any bonding interaction between the vanadiums.

A single-crystal $X$-ray structure analysis of 5 a revealed each vanadium atom has a distorted trigonal-bipyramidal structure $(\tau=$ $0.88)^{[8]}$ through $\mu$-phenoxido-bridging in the crystal packing. The (imido)vanadium $(\mathrm{V})$ compounds with three 2,6dimethylphenoxide ligands were reported to have a monomeric structure by Nomura group. ${ }^{[4]}$ On the contrary, the (imido)vanadium( $\mathrm{V}$ ) compound with three 2,6-difluorophenoxide ligands was found to form the dimeric structure $\mathbf{5 b}$ instead of the monomeric one (Figure 2a). This finding was caused by the Lewis acidity of vanadium center which was enhanced by the electronwithdrawing properties of the 2,6-difluorophenoxide ligand. The compound 5a has the V1-N1 distance of 1.656(3) $\AA$ and the nearly linear V1-N1-C1 angle of $177.6(3)^{\circ}$, indicating an sp-hybridized character in the imido nitrogen similarly to other (imido)vanadium(V) compounds. The V1-O2 and V1-O3 bond lengths of $\mathbf{5 a}$ on nonbridging phenoxide ligands are shorter than those of $3 \mathbf{a}$ due to the stronger Lewis acidity of vanadium center

For internal use, please do not delete. Submitted_Manuscript 
caused by coordination of three 2,6-difluorophenoxide ligands. In the case of bridging alkoxide ligands, the $\mathrm{V} 1-\mathrm{O} 1$ and $\mathrm{V} 1-\mathrm{O} 1^{*}$ bond lengths of $\mathbf{5 a}$ were found to be longer than those of $\mathbf{3 a}$. These results were probably caused by a weaker coordination of the bridging phenoxide ligands to the vanadium centers than the bridging isopropoxide ligands in the dimeric structure. In the (imido)vanadium(V) compound $\mathbf{5 a}$, Intramolecular $\mathrm{CH}-\pi$ interactions of hydrogen atom at the ortho position of the methoxyphenyl moiety with phenoxide ligands are also observed. One hydrogen atom of the methoxyphenyl moiety interacts with non-bridging phenoxide ligand, another hydrogen atom with the bridging phenoxide ligand as shown in Figure $2 \mathrm{~b}$.

\section{Conclusions}

The structural characterization of (arylimido)vanadium(IV) compounds $\mathbf{2 a}, \mathbf{3 a}$, and $\mathbf{5 a}$ with 2,6-difluorophenoxide ligands were demonstrated to evaluate the effect of phenoxide ligands in the self-association. The crystal strucures of $\mathbf{2} \mathbf{a}$ and $\mathbf{3 a}$ confirmed the formation of the $\mu$-isopropoxido-bridged dimeric structures $\mathbf{2 b}$ and $\mathbf{3 b}$, wherein each vanadium atom has a trigonal-bipyramidal geometry with the imido and the bridging isopropoxide ligand in the apical positions. These results indicate that dimeric species are more likely to form the $\mu$-isopropoxido-bridging structure rather than the $\mu$-phenoxido-bridging one. On the contrary, the crystal strucure of 5 a revealed the formation of the $\mu$-phenoxidobridging structure $\mathbf{5 b}$ with a trigonal-bipyramidal geometry, wherein the imido and the bridging phenoxide ligand existed in apical positions at each vanadium. The abcence of isopropoxide ligand lead to the $\mu$-phenoxido-bridging structure rather than monomeric one in the crystal packing. Studies on the application of the (arylimido)vanadium(V) compounds as a catalyst are now in progress.

\section{Experimental Section}

General Considerations. All manipulations were carried out under a nitrogen atmosphere in a drybox or using standard Schlenk techniques. All reagents and solvents were purchased from commercial sources and were further purified by the standard methods, if necessary. ${ }^{1} \mathrm{H}$ and ${ }^{13} \mathrm{C}$ NMR spectra were recorded on a JEOL JNM-ECP $400\left({ }^{1} \mathrm{H}\right.$ NMR, $400 \mathrm{MHz} ;{ }^{13} \mathrm{C}$ NMR, $100 \mathrm{MHz}$ ) spectrometer. The chemical shifts were referenced to the residual resonances of deuterated solvents. ${ }^{51} \mathrm{~V}$ NMR spectra were obtained with a JEOL JNM-ECP $400(105 \mathrm{MHz})$ spectrometer with $\mathrm{VOCl}_{3}$ as an external standard. The (arylimido)vanadium $(\mathrm{V})$ compound $[(p-$ $\left.\left.\mathrm{MeOC}_{6} \mathrm{H}_{4} \mathrm{~N}\right) \mathrm{V}\left(\mathrm{O}^{\prime} \mathrm{Pr}\right)_{3}\right](\mathbf{1})^{[3 \mathrm{~m}]}$ and $\left[\left(p-\mathrm{MeOC}_{6} \mathrm{H}_{4} \mathrm{~N}\right) \mathrm{VCl}_{3}\right](4)^{[3 \mathrm{~b}]}$ were obtained as reported.

$\left[\left(p-\mathrm{MeOC}_{6} \mathrm{H}_{4} \mathbf{N}\right) \mathbf{V}\left(\mathbf{O}^{\prime} \mathrm{Pr}\right)_{2}\left(\mathbf{O}-2,6-\mathrm{F}_{2} \mathrm{Ph}\right)\right] \quad(2 \mathrm{a}) . \quad A$ mixture of $[(p-$ $\left.\left.\mathrm{MeOC}_{6} \mathrm{H}_{4} \mathrm{~N}\right) \mathrm{V}(\mathrm{O} \mathrm{Pr})_{3}\right]$ (1) $(70 \mathrm{mg}, 0.2 \mathrm{mmol})$ and 2,6-difluorophenol $(26 \mathrm{mg}$, $0.2 \mathrm{mmol}$ ) was stirred in dichloromethane $(4.0 \mathrm{~mL})$ under a nitrogen atmosphere at room temperature for $4 \mathrm{~h}$. After evaporation of the solution, the resultant solid was purified by the reprecipitation from dichloromethane/ether at $-30^{\circ} \mathrm{C}$. Thus-obtained solid was recrystallized from toluene/hexane at $-30{ }^{\circ} \mathrm{C}$, giving $\left[\left(p-\mathrm{MeOC}_{6} \mathrm{H}_{4} \mathrm{~N}\right) \mathrm{V}\left(\mathrm{O} \mathrm{O}^{\prime} \mathrm{Pr}\right)_{2}(\mathrm{O}-2,6-\right.$ $\left.\left.\mathrm{F}_{2} \mathrm{Ph}\right)\right](\mathbf{2 a})$ as an orange crystal $(51 \mathrm{mg}, 0.12 \mathrm{mmol})$. 2a: yield $61 \% ;{ }^{1} \mathrm{H}$ $\operatorname{NMR}\left(400 \mathrm{MHz}, \mathrm{CDCl}_{3}\right) \delta 6.88-6.68(\mathrm{~m}, 3 \mathrm{H}), 6.54(\mathrm{br}, 4 \mathrm{H}), 5.44(\mathrm{br}, 2 \mathrm{H})$, $3.73(\mathrm{~s}, 3 \mathrm{H}), 1.47(\mathrm{br} \mathrm{d}, 12 \mathrm{H}, J=4.1 \mathrm{~Hz}) ;{ }^{13} \mathrm{C} \mathrm{NMR}\left(100 \mathrm{MHz}, \mathrm{CDCl}_{3}\right)$ 157.6, 154.6, 152.1, 127.5, 118.9, 113.1, 111.1, 82.1, 55.4, 26.6 ppm; ${ }^{51} \mathrm{~V}$ NMR (105 MHz, $\left.\mathrm{CDCl}_{3}\right)-532 \mathrm{ppm}$. Anal. Calcd for $\mathrm{C}_{19} \mathrm{H}_{24} \mathrm{~F}_{2} \mathrm{NO}_{4} \mathrm{~V}$ : C,54.42; $\mathrm{H}$, 5.77 ; N, 3.34\%. Found: C, 53.89; H, 5.32; N, 3.32\%.

$\left[\left(p-\mathrm{MeOC}_{6} \mathrm{H}_{4} \mathrm{~N}\right) \mathrm{V}\left(\mathrm{O}^{\prime} \mathrm{Pr}\right)\left(\mathrm{O}-2,6-\mathrm{F}_{2} \mathrm{Ph}\right)_{2}\right] \quad$ (3a). A mixture of $[(p-$ $\left.\left.\mathrm{MeOC}_{6} \mathrm{H}_{4} \mathrm{~N}\right) \mathrm{V}\left(\mathrm{O}^{\prime} \mathrm{Pr}\right)_{3}\right]$ (1) $(70 \mathrm{mg}, 0.2 \mathrm{mmol})$ and 2,6-difluorophenol (52 mg, $0.4 \mathrm{mmol})$ was stirred in dichloromethane $(4.0 \mathrm{~mL})$ under a nitrogen atmosphere at room temperature for $4 \mathrm{~h}$. After evaporation of the solution, the resultant solid was purified by the reprecipitation from dichloromethane/ether at $-30{ }^{\circ} \mathrm{C}$. Thus-obtained solid was recrystallized from dichloromethane/hexane at room temperature, giving $[(p-$ $\left.\left.\mathrm{MeOC}_{6} \mathrm{H}_{4} \mathrm{~N}\right) \mathrm{V}\left(\mathrm{O}^{\prime} \mathrm{Pr}\right)\left(\mathrm{O}-2,6-\mathrm{F}_{2} \mathrm{Ph}\right)_{2}\right](3 \mathrm{a})$ as a red crystal $(65 \mathrm{mg}, 0.13 \mathrm{mmol})$. 3a: yield $65 \%$; ${ }^{1} \mathrm{H}$ NMR $\left(400 \mathrm{MHz}, \mathrm{CDCl}_{3}\right) \delta 6.86-6.68(\mathrm{~m}, 6 \mathrm{H}), 6.40(\mathrm{br}$, $4 \mathrm{H}), 5.68(\mathrm{br}, 1 \mathrm{H}), 3.68(\mathrm{~s}, 3 \mathrm{H}), 1.54(\mathrm{br} \mathrm{d}, 6 \mathrm{H}, J=5.0 \mathrm{~Hz}) ;{ }^{13} \mathrm{C}$ NMR $(100$ $\left.\mathrm{MHz}, \mathrm{CDCl}_{3}\right)$ 158.4, 154.0, 152.4, 146.2, 128.4, 119.8, 113.0, 111.1, 84.6, 55.4, $26.4 \mathrm{ppm} ;{ }^{51} \mathrm{~V}$ NMR $\left(105 \mathrm{MHz}, \mathrm{CDCl}_{3}\right)-367 \mathrm{ppm}$. Anal. Calcd for $\mathrm{C}_{22} \mathrm{H}_{20} \mathrm{~F}_{4} \mathrm{NO}_{4} \mathrm{~V}$ : C,54.00; $\mathrm{H}, 4.12 ; \mathrm{N}, 2.86 \%$. Found: $\mathrm{C}, 53.48 ; \mathrm{H}, 4.19 ; \mathrm{N}$, $2.98 \%$.

[(p-MeOC $\left.\left.{ }_{6} \mathrm{H}_{4} \mathrm{~N}\right) \mathrm{V}\left(\mathrm{O}-2,6-\mathrm{F}_{2} \mathrm{Ph}\right)_{3}\right](5 \mathrm{a})$. A mixture of $\left[\left(p-\mathrm{MeOC}_{6} \mathrm{H}_{4} \mathrm{~N}\right) \mathrm{VCl}_{3}\right]$ (4) $(56 \mathrm{mg}, 0.2 \mathrm{mmol}$ ) and lithium 2,6-difluorophenoxide ( $82 \mathrm{mg}, 0.6 \mathrm{mmol})$ was stirred in dichloromethane $(4.0 \mathrm{~mL})$ under a nitrogen atmosphere at room temperature for $4 \mathrm{~h}$. After evaporation of the solution, the resulting solid was extracted with ether/hexane and the solvent was removed in vacuo. The obtained solid was recrystallized from ether/hexane at room temperature, giving $\left[\left(p-\mathrm{MeOC}_{6} \mathrm{H}_{4} \mathrm{~N}\right) \mathrm{V}\left(\mathrm{O}-2,6-\mathrm{F}_{2} \mathrm{Ph}\right)_{3}\right](5 \mathbf{a})$ as a reddish brown crystal $(66 \mathrm{mg}, 0.12 \mathrm{mmol})$. 5a: yield $59 \%$; ${ }^{1} \mathrm{H}$ NMR $(400 \mathrm{MHz}$, $\left.\mathrm{CDCl}_{3}\right) \delta 6.95-6.27(\mathrm{~m}, 9 \mathrm{H}), 6.00(\mathrm{~d}, 2 \mathrm{H}, J=8.7 \mathrm{~Hz}), 5.61(\mathrm{~d}, 2 \mathrm{H}, J=8.7$ $\mathrm{Hz}), 3.54(\mathrm{~s}, 3 \mathrm{H}) ;{ }^{13} \mathrm{C}$ NMR $\left(100 \mathrm{MHz}, \mathrm{CDCl}_{3}\right) 153.7,151.2,146.1,129.4$, 122.0, 112.8, 111.3, 55.4 ppm; ${ }^{51} \mathrm{~V}$ NMR (105 MHz, $\left.\mathrm{CDCl}_{3}\right)-241$ ppm. Anal. Calcd for $\mathrm{C}_{25} \mathrm{H}_{16} \mathrm{~F}_{6} \mathrm{NO}_{4} \mathrm{~V}$ : C,53.68; $\mathrm{H}, 2.88 ; \mathrm{N}, 2.50 \%$. Found: $\mathrm{C}, 53.71 ; \mathrm{H}$, $3.42 ; \mathrm{N}, 2.55 \%$

Single-crystal X-ray Structure Determination. All measurements for $\mathbf{2 a}$, 3a and 5a were made on a Rigaku R-AXIS RAPID diffractometer using graphite monochromated MoK $\alpha$ radiation. The structures of $2 a, 3 a$ and $5 a$ were solved by direct methods ${ }^{[9]}$ and expanded using Fourier techniques. All calculations were performed using the CrystalStructure crystallographic software package ${ }^{[10]}$ except for the refinement, which was performed using SHELXL. ${ }^{[11]}$ The non-hydrogen atoms were refined anisotropically. The $\mathrm{H}$ atoms were placed in idealized positions and allowed to ride with the $C$ atoms to which each was bonded. Crystallographic details are given in Table 1. Crystallographic data (excluding structure factors) for the structures reported in this paper have been deposited with the Cambridge Crystallographic Data Centre as supplementary publication no. CCDC1536994 for 2a, CCDC-962292 for 3a and CCDC-1536995 for 5a. Copies of the data can be obtained free of charge on application to CCDC, 12 Union Road, Cambridge CB2 1EZ, UK [Fax: (internat.) +44-1223/336-033; E-mail: deposit@ccdc.cam.ac.uk].

\section{Acknowledgements}

This work was supported by ACT-C from JST, Japan. We thank Dr Hideki Sugimoto and Prof. Shinobu Itoh for the singlecrystal X-ray structure determination. Thanks are due to the Analytical Center, Graduate School of Engineering, Osaka University.

Keywords: (Arylimido)vanadium(V) • Self-association • Alkoxido Bridging $\cdot \mathrm{CH}-\pi$ Interaction 
[1] a) D. E. Wigley, in Progress in Inorganic Chemistry, Vol. 42 (Ed.: Karlin, K. D.), Wiley-Interscience, New York, 1994, pp. 239-482; b) W. A. Nugent and J. M. Mayer, Metal-Ligand Multiple Bonds, Wiley-Interscience, New York, 1998.

[2] T. R. Cundari, Chem. Rev. 2000, 100, 807-818.

[3] a) F. Preuss, W. Towae, Z. Naturforsch., Teil B 1981, 36, 1130-1135; b) E. A. Maatta, Inorg. Chem. 1984, 23, 2560-2561; c) D. D. Devore, J. D. Lichtenhan, F. Takusagawa, E. A. Maatta, J. Am. Chem. Soc. 1987, 109 7408-7416; d) A. Hills, D. L. Hughes, G. J. Leigh, R. Prieto-Alc ónd, J. Chem. Soc. Dalton Trans. 1993, 23, 3609-3617; e) G. A. Solan, P. G. Cozzi, C. Floriani, A. Chiesi-Villa, C. Rizzoli, Organometallics 1994, 13 2572-2574; f) J.-K. F. Buijink, A. Meetsma, J. H. Teuben, H. Kooijman, A. L. Spek, J. Organomet. Chem. 1995, 497, 161-170; g) M. G. Fickes, W. M. Davis, C. C. Cummins, J. Am. Chem. Soc. 1995, 117, 6384-6385 h) P. T. Witte, A. Meetsma, B. Hessen, J. Am. Chem. Soc. 1997, 119 10561-10562; i) D. E. Wheeler, J.-F. Wu, E. A. Maatta, Polyhedron 1998, 17, 969-976; j) M. Lutz, H. Hagen, A. M. M. Schreurs, A. L. Spek, G. van Koten, Acta Crystallogr. Sect. C 1999, 55, 1636-1639; k) T. Moriuchi, K. Ishino, T. Hirao, Chem. Lett. 2007, 1486-1487; I) T. Moriuchi, T. Beppu, K. Ishino, M. Nishina, T. Hirao, Eur. J. Inorg. Chem. 2008, 1969-1973 m) T. Moriuchi, K. Ishino, T. Beppu, M. Nishina, T. Hirao, Inorg. Chem. 2008, 47, 7638-7643; n) D. Rehder, Coord. Chem. Rev. 2008, 252, 22092223; о) T. Moriuchi, T. Hirao, Pure Appl. Chem. 2009, 81, 1187-1195; p) T. Moriuchi, M. Nishina, T. Hirao, Angew. Chem. Int. Ed. Engl. 2010, 49, 83-86; q) K.A. Rufanov, J. Kipke, J. Sundermeyer, Dalton Trans. 2011, 40, 1990-1997; r) M. Nishina, T. Moriuchi, T. Hirao, Bull. Chem. Soc. Jpn. 2012, 85, 606-612. s) T. Sakuramoto, T. Moriuchi, T. Hirao, J. Inorg. Biochem. 2016, 164, 77-81; t) T. Sakuramoto, T. Hirao, T. Moriuchi, Chem. Lett. 2017, 46, 844-847; u) T. Sakuramoto, T. Hirao, T. Moriuchi, ChemistrySelect 2017, 2, 6618-6622.

[4] For references after 2005, see; a) Y. Sato, Y. Nakayama, H. Yasuda, J. Appl. Polym. Sci. 2005, 97, 1008-1015; b) H. R. Bigmore, M. A. Zuideveld, R. M. Kowalczyk, A. R. Cowley, M. Kranenburg, E. J. L. Mclnnes, P. Mountford, Inorg. Chem. 2006, 45, 6411-6423; c) C. Redshaw, M. A. Rowan, L. Warford, D. M. Homden, A. Arbaoui, M. R. J. Elsegood, S. H. Dale, T. Yamato, C. P. Casas, S. Matsui, S. Matsuura, Chem. Eur. J. 2007, 13, 1090-1107; d) D. M. Homden, C. Redshaw, D. L. Hughes,
Inorg. Chem. 2007, 46, 10827-10839; e) D. Homden, C. Redshaw, J. A Wright, D. L. Hughes, M. R. J. Elsegood, Inorg. Chem. 2008, 47, 5799 5814; f) W. Zhang, K. Nomura, Inorg. Chem. 2008, 47, 6482-6492 g) W. Zhang, K. Nomura, Organometallics 2008, 27, 6400-6402 h) A. Arbaoui, C. Redshow, D. M. Homden, J. A. Wright, M. R. J. Elsegood, Dalton Trans. 2009, 8911-8922; i) C. Redshow, Dalton Trans. 2010, 39, 55955604; j) L. Clowes, C. Redshaw, D. L. Hughes, Inorg. Chem. 2011, 50, 7838-7845; k) K. Nomura, S. Zhang, Chem. Rev. 2011, 111, 2342-2362; I) X. Hou, K Nomura, J. Am. Chem. Soc., 2016, 138, 11840-11849; m) K Nomura, X. Hou, Dalton Trans. 2017,46, 12-24.

[5] a) J. de With, A. D. Horton, A. G. Orpen, Organometallics 1990, 9, 22072209; b) J. de With, A. D. Horton, Angew. Chem. Int. Ed. Engl. 1993, 32 903-905; c) T. R. Cundari, Organometallics 1994, 13, 2987-2994; d) S. Zhang, M. Tamm, K. Nomura, Organometallics 2011, 30, 2712-2720.

[6] For references after 2000, see; a) C. Peters, F. Tabellion, M. Schröder U. Bergsträßer, F. Preuss, M. Regitz, Synthesis 2000, 417-428; b) F. Montilla, A. Pastor, A. Galindo, J. Organomet. Chem. 2004, 689, 993996; c) C. Lorber, R. Choukroun, L. Vendier, Organometallics 2004, 23 1845-1850; d) F. Montilla, D. del Río, A. Pastor, A. Galindo, Organometallics 2006, 25, 4996-5002; e) J. R. Fernández,F. C. Hermosilla, A. Antiñolo, C. A. Moreno, A. M. Rodrıguez, I. L. Solera, A. Otero, Dalton Trans. 2010, 39, 6419-6425; f) M. Nishina, T. Moriuchi, T. Hirao, Dalton Trans. 2010, 39, 9936-9940.

[7] S. Dürr, B. Bechlars, U. Radius, Inorg. Chim. Acta 2006, 359, 4215-4226.

[8] The structural parameter $\tau=(\beta-\alpha) / 60$ for the coordination geometry of the five-coordinated complex proposed by Addison and Reedijk where $\alpha$ and $\beta$ represent two basal angles $(\beta>\alpha)$. The parameters for an ideal square pyramidal and trigonal bipyramidal geometries are $\tau=0(\alpha=\beta=$ $\left.180^{\circ}\right)$ and $\tau=1\left(\alpha=120^{\circ}\right.$ and $\left.\beta=180^{\circ}\right)$, respectively. A. W. Addison, T. N. Rao, J. Reedijk, J. van Rijn, G. C. Verschoor, J. Chem. Soc. Dalton Trans. 1984, 1349-1356

[9] M. C. Burla, R. Caliandro, M. Camalli, B. Carrozzini, G. L. Cascarano, L. De Caro, C. Giacovazzo, G. Polidori, R. Spagna, J. Appl. Cryst. 2005 38, 381-388.

[10] CrystalStructure 4.2.2: Crystal Structure Analysis Package, Rigaku Corporation (2000-2016). Tokyo 196-8666, Japan.

[11] G. M. Sheldrick, Acta Crystallogr. Sec. A 2008, 64, 112-122. 
Entry for the Table of Contents (Please choose one layout)

\section{FULL PAPER}

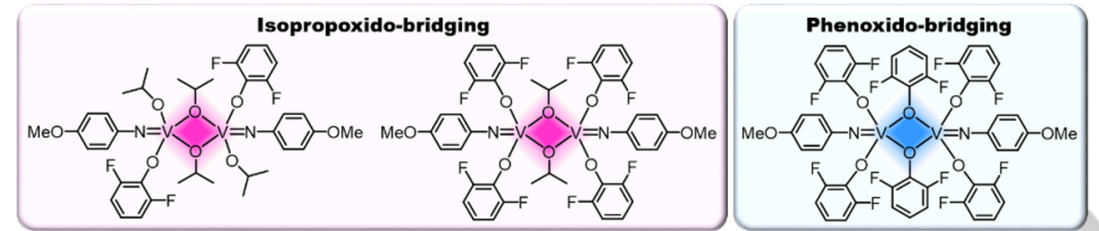

The (arylimido)vanadium(V) compounds bearing one or two 2,6-difluorophenoxide ligands were found to form $\mu$-Isopropoxido-bridged dimeric structures selectively. On the contrary, $\mu$-phenoxido-bridged dimeric structure was observed in (arylimido)vanadium(V) compound with three 2,6-difluorophenoxide ligands.
Toshiyuki Moriuchi, * Takashi

Sakuramoto, Masafumi Nishina, Ryota

Kawai, and Toshikazu Hirao*

Page No. - Page No.

Structural Characterization of (Arylimido)vanadium(V) Compounds with 2,6-Difluorophenoxide Ligand

For internal use, please do not delete. Submitted_Manuscript 